\title{
cDNA Sequence Analysis and Structural Phylogenetic Tree of Novel Myoglobin from Striped Snake-Head Fish (Ophicephalus striatus)
}

\section{CHATRACHATCHAYA CHOTICHAYAPONG ${ }^{1}$, SAKSIT CHANTHAI ${ }^{1 *}$, NISON SATTAYASAI ${ }^{2}$, NOBUYUKI KANZAWA ${ }^{3}$, TORU TAMIYA ${ }^{3}$ and TAKAHIDE TSUCHIYA ${ }^{3}$}

\author{
${ }^{1}$ Center of Excellence for Innovation in Chemistry, Department of Chemistry, \\ Faculty of Science, Khon Kaen University, Khon Kaen 40002, Thailand. \\ ${ }^{2}$ Department of Biochemistry, Faculty of Science, Khon Kaen University, \\ Khon Kaen 40002, Thailand. \\ ${ }^{3}$ Department of Materials and Life Sciences, Faculty of Science and Technology, \\ Sophia University, Tokyo 102-8554, Japan. \\ ${ }^{*}$ Corresponding author E-mail: sakcha2@ @ku.ac.th \\ http://dx.doi.org/10.13005/ojc/320102
}

(Received: January 27, 2016; Accepted: March 05, 2016)

\begin{abstract}
Primary structure of myoglobin $(\mathrm{Mb})$ from ordinary muscle of striped snake-head fish (Ophicephalus striatus) was studied. Sequence analysis of cloned cDNA revealed two lengths of nucleotide sequences different in $3^{\prime}$ untranslated regions, Mbl gene and Mbll gene. In accordance to amino acid coding region, both genes encoded protein with 145 amino acid residues which were different in two amino acid residues at position 114 and 117, indicating Mb isoforms. They are very close to those of various species of fish Mbs and very identical to some marine Mbs. There are amino acid differences among the fish Mbs and other Mbs that occur in the highly conserved regions in fish species. The replacement of alanine with serine 59 in fish species, adjacent to histidine 60 may contribute to the reversible binding of oxygen. Lysine was replaced by asparagine at position 93 which directly binds to the heme. The fish Mbs contain two cysteine residues. One of cysteine residue locates at the terminal of the polypeptide chain which may possibly contribute to internal disulfide interaction and thus forms tightly folded structure. It is implied that the fish Mb might be a novel protein with strong intramolecular bonding.
\end{abstract}

Key words: Myoglobin; Striped snake-head fish; cDNA sequence; Phylogenetic tree; Oxygen binding.

\section{INTRODUCTION}

Striped snake-head fish (Ophicephalus striatus) is well-known freshwater fish which is widely habitat distributing in Thailand and other tropical areas. This fish is among the very few aquatic vertebrates that are able to tolerate periods of severe environmental hypoxia, both diurnally and 
for prolonged periods. Particularly, it is a kind of fish which is tolerant of water lacking in dissolved oxygen and can survive without water environment such as mud for a number of mouths as long as the skin and breathing apparatus are kept moist ${ }^{1}$. Myoglobin (Mb), a protein which is closely related of hypoxic tolerance of the fish, may have some interesting characteristic and their physicochemical properties. $\mathrm{Mb}$ is generally considered as an important intracellular oxygen binding hemoprotein found in skeletal and cardiac muscle tissues. It exists in a wide variety of species such as diving mammals ${ }^{2-4}$ and also found in amphibians ${ }^{5}$, teleosts ${ }^{6}$, chondrichthid fish ${ }^{7,8}$ and some lower species ${ }^{9,10}$. Structurally, it is a compact and globular protein whose backbone structure consists of eight-helical segments designed $A$ through $\mathrm{H}$ and the heme as a prosthetic group ${ }^{11}$. The heme is positioned in a hydrophobic heme pocket and binds directly to the imidazole group of proximal histidine through oxygen coordinate binding ${ }^{12,13}$. The primary structure of $\mathrm{Mb}$ is the order in which its 146153 amino acids are joined depending on species. It posses its functional property preliminarily as a temporary storing of excess oxygen for metabolic respiration in order to delay and prevent the onset of anoxia by releasing of oxygen when perfusion levels of oxygen in mitochondria fall to critical low values or high oxygen demand ${ }^{12}$. It also plays a role in facilitating oxygen transport into tissues by diffusion from sercolemma to the mitochondria of heart and red muscle cells. The biological functions of $\mathrm{Mb}$ depend critically on the chemical equilibrium of oxygen binding to the iron that is chelated to the heme group within the protein ${ }^{14,15}$. Moreover, it is the most important determinant for the characteristic color of muscle tissue depending on its redox state and concentration ${ }^{16}$. Thus, different kind of animals living in the different habitat shows a difference in their properties ${ }^{17-23}$.

As far as fish $\mathrm{Mb}$ is concerned, it is present in most fishes, but its amount varies widely. Mb content is correlated with species capacities for sustained aerobic exercise and also depends on breed, sex and age of animal, training and nature of nutrition, oxygen availability, blood circulation and muscle type 8,24-27. Thus, the protein of fish species is interesting to study because it provides an excellent system in which to study the natural variation of $\mathrm{Mb}$ function, and to understand the interrelationship between structure and function ${ }^{28-32}$. As well known, all function of $\mathrm{Mb}$ is related with their structure. The variation in amino acid sequences of $\mathrm{Mb}$ influences their chemical and thermal stability ${ }^{21,25,31-33}$. The striped snake-head fish is mostly found as the hypoxic tolerant fish. Therefore, its structural property is thought to have interesting characteristic and relatively high stability. Based on functional aspect including structure and stability relationship, this fish $\mathrm{Mb}$ is, however, no report yet at the present. This research study is then aimed to investigate structural properties related to folding stability.

Therefore, this study was aimed to determine primary structure of the fish protein via cDNA sequencing through an extraction of total RNA from the frozen fish muscle and studying of primers designation for the fish Mb cDNA synthesis by reversed translated partial peptide sequences obtained from the striped snake-head $\mathrm{Mb}$ and conserved regions of the published sequences from other fish species. We first synthesized and amplified the fish Mb cDNA using OneStep RT-PCR kit. The complete nucleotide sequence was done using the SMART RACE cDNA amplification kit, resulting in its complete amino acids sequence by deduction from the nucleotide sequence to understand the evolution of the fish by its construction of the phylogenic tree.

\section{MATERIALS AND METHODS}

\section{Nucleotide sequence analysis \\ Primer design}

Specific oligonucleotide primers were designed by deduction from nucleotide sequences of conserved regions of published sequences from various fish $\mathrm{Mbs}^{34,35}$. Three partial peptide sequences obtained by $\mathrm{N}$-terminal sequence analysis were used to design degenerate primers. Primer sequences used for the experiment are listed in Table 1. The primer pairs used for amplification of the striped snake-head fish Mb DNA are shown in Table 2.

\section{Extraction of RNA and cDNA synthesis}

Ordinary muscle of striped snake-head fish were excised and placed in sterile, RNase free microcentrifuge tubes, then frozen immediately in liquid nitrogen. Total RNA was extracted from approximately 50-100 mg using TRIZOL reagent 
Table 1:Primer sequences used for determination of nucleotide sequence

\begin{tabular}{|c|c|c|}
\hline \multicolumn{2}{|l|}{ Primer name } & Sequences $\left(5^{\prime} \rightarrow 3^{\prime}\right)$ \\
\hline \multicolumn{3}{|c|}{ RT-PCR and Cloning primers } \\
\hline \multicolumn{2}{|c|}{ Myg_f1 } & ATCACACAGGACATTTTACTACTC \\
\hline \multicolumn{2}{|l|}{ Myg_r1 } & TCGGCAAAACTTTGTGAATCTG \\
\hline \multicolumn{2}{|l|}{ Myg_f2 } & CAGATAATGGCTGACTTTGACATG \\
\hline \multicolumn{2}{|l|}{ Myg_r2* } & TTYTTDATNGGDATRTTRTG \\
\hline \multicolumn{2}{|l|}{ Myg_r2nested" } & TTDATNGGDATRTTRTGYTT \\
\hline \multicolumn{2}{|l|}{ Myg_f3* } & TTYGTNWSNATHCCNYTNGC \\
\hline \multicolumn{2}{|l|}{ Myg_f3nested } & GTNWSNATHCCNYTNGCNGA \\
\hline \multicolumn{2}{|c|}{ Myg_r3* } & GCNGCRTGNSWNCCRTANGC \\
\hline \multirow{2}{*}{\multicolumn{2}{|c|}{$\begin{array}{l}\text { Myg_r3nested" } \\
3^{\prime} \text { - and 5'-RACE primers }\end{array}$}} & GCRTGNSWNCCRTANGCYTT \\
\hline & & $3^{\prime}-$ and $5^{\prime}-$ RACE primers \\
\hline \multicolumn{2}{|c|}{ SMARTer II A primers } & AAGCAGTGGTATCAACGCAGAGTACXXXXX \\
\hline \multicolumn{2}{|c|}{$3^{\prime}-$ CDS primer $A$} & AAGCAGTGGTATCAACGCAGAGTAC $(T)_{30}$ VN \\
\hline \multicolumn{2}{|c|}{ Myg_3R } & AAGCCACGGTGCCACGGTGCTGAATAAACT \\
\hline \multirow{2}{*}{\multicolumn{2}{|c|}{$\begin{array}{l}\text { Myg_3R nested } \\
5^{\prime}-\text { CDS primer A }\end{array}$}} & AGCCACGGTGCCACGGTGCTGAATAAACTA \\
\hline & & $(\mathrm{T})_{25} \mathrm{VN}$ \\
\hline \multicolumn{2}{|c|}{ Myg_5R } & TTACTGCCAGAGGTTTGACGGATGGAAGCGT \\
\hline \multicolumn{2}{|c|}{ Myg_5R nested } & TACTGCCAGAGGTTTGAGGATGGAAGCGTG \\
\hline \multicolumn{3}{|c|}{$\begin{array}{l}\text { *The degenerated primers } \\
\mathrm{N}=\mathrm{A}, \mathrm{C}, \mathrm{G} \text {, or } \mathrm{T} ; \mathrm{V}=\mathrm{A}, \mathrm{G}, \text { or } \mathrm{C} ; \mathrm{Y}=\mathrm{C} \text { or } \mathrm{T} ; \mathrm{W}=\mathrm{A} \text { or } \mathrm{T} ; \mathrm{S}=\mathrm{C} \text { or } \mathrm{G} ; \mathrm{D}=\mathrm{A}, \mathrm{G} \text { or } \mathrm{T}\end{array}$} \\
\hline \multicolumn{3}{|c|}{$\begin{array}{l}\text { Table 2: Primer pairs used for amplification of striped snake-head fish } \\
\text { DNA. F and } R \text { strand for forward and reward primers, respectively }\end{array}$} \\
\hline Primer pairs & Primer names & Primer sequence $\left(5^{\prime} \rightarrow 3^{\prime}\right)$ \\
\hline \multirow[t]{2}{*}{$\mathrm{P}_{1}$} & Myg_f1 & F- ATCACACAGGACATTTTACTACTC \\
\hline & Myg_r1 & R- TCGGCAAAACTTTGTGAATCTG \\
\hline \multirow[t]{2}{*}{$\mathrm{P}_{2}$} & Myg_f2 & F- CAGATAATGGCTGACTTTGACATG \\
\hline & Myg_r1 & R- TCGGCAAAACTTTGTGAATCTG \\
\hline \multirow[t]{2}{*}{$\mathrm{P}_{3}$} & Myg_f3 & F-TTYGTNWSNATHCCNYTNGC \\
\hline & Myg_r2 & R- TTYTTDATNGGDATRTTRTG \\
\hline \multirow[t]{2}{*}{$\mathrm{P}_{4}$} & Myg_f3 & F- TTYGTNWSNATHCCNYTNGC \\
\hline & Myg_r3 & R- GCNGCRTGNSWNCCRTANGC \\
\hline \multirow[t]{2}{*}{$P_{1-1}$} & Myg_f2 & F- CAGATAATGGCTGACTTTGACATG \\
\hline & Myg_r1 & R- TCGGCAAAACTTTGTGAATCTG \\
\hline \multirow[t]{2}{*}{$P_{1-2}$} & Myg_f2 & F- CAGATAATGGCTGACTTTGACATG \\
\hline & Myg_r2 & R- TTYTTDATNGGDATRTTRTG \\
\hline \multirow[t]{2}{*}{$P_{2-2}$} & Myg_f2 & F- CAGATAATGGCTGACTTTGACATG \\
\hline & Myg_r2 & R- TTYTTDATNGGDATRTTRTG \\
\hline$P_{3-2}$ & Myg_f3nested & F- GTNWSNATHCCNYTNGCNGA \\
\hline & Myg_r2nested & R- TTDATNGGDATRTTRTGYTT \\
\hline$P_{4-2}$ & Myg_f3nested & F- GTNWSNATHCCNYTNGCNGA \\
\hline & Myg_r3nested & R- GCRTGNSWNCCRTANGCYTT \\
\hline
\end{tabular}


(Invitrogent) according to manufacturer's instruction. Total RNA was determined for its concentration by measuring absorbance at $260 \mathrm{~nm}$ using Hitachi UV2000A spectrophotometer and checked for the quality by electrophoresis on $1.5 \%$ denaturing formaldehyde agarose gel.

\section{Cloning and DNA sequencing of the fish Mb}

cDNA of the protein was synthesized and amplified using the OneStep $®$ RT-PCR kit. Reverse transcription and PCR were carried out sequentially in the same tube on a thermo cycler. The 4 pairs of specific primer including $\mathrm{P}_{1}, \mathrm{P}_{2}, \mathrm{P}_{3}$ or $\mathrm{P}_{4}$ were separately used for making a first strand cDNA. The

Table 3: Amino acid compositions of the fish $\mathrm{Mb}$

\begin{tabular}{lcc}
\hline Amino acid & \multicolumn{2}{c}{ Number } \\
& Mbl & Mbll \\
\hline Ala, A & 17 & 17 \\
Cys, C & 2 & 2 \\
Asp, D & 6 & 6 \\
Glu, E & 8 & 8 \\
Phe, F & 5 & 5 \\
Gly, G & 8 & 8 \\
His, H & 5 & 5 \\
Ile, I & 10 & 10 \\
Lys, K & 11 & 11 \\
Leu, L & 18 & 18 \\
Met, M & 3 & 3 \\
Asn, N & 7 & 7 \\
Pro, P & 8 & 8 \\
Gln, Q & 3 & 3 \\
Arg, R & 4 & 4 \\
Ser, S & 8 & 8 \\
Thr, T & 9 & 9 \\
Val, V & 10 & 10 \\
Trp, W & 1 & 1 \\
Tyr, Y & 2 & 2 \\
\hline
\end{tabular}

reverse transcriptase reaction was carried out at 50 ${ }^{\circ} \mathrm{C}$ for 30 min to performed cDNA then followed by $95^{\circ} \mathrm{C}$ for $15 \mathrm{~min}$ to inactivate reverse transcriptase and simultaneously to hot-start Tag DNA polymerase for amplification of cDNA. The PCR amplification was performed for 30 cycles at $94^{\circ} \mathrm{C}$ for $30 \mathrm{~s}$, primer annealing at $55^{\circ} \mathrm{C}$ for $30 \mathrm{~s}$, and primer extension at $72^{\circ} \mathrm{C}$ for $1 \mathrm{~min}$. The products were analyzed by $1.5 \%$ agarose gel electrophoresis.

Each of PCR products from the first amplification referred as $\mathrm{P}_{1}, \mathrm{P}_{2}, \mathrm{P}_{3}$ or $\mathrm{P}_{4}$ was reamplified with the same condition using the specific internal primers. The $P_{1}$ product was separately amplified using 2 specific primer pairs, $P_{1-1}$ and $P_{1-2}$.

The $\mathrm{P}_{2}, \mathrm{P}_{3}$ and $\mathrm{P}_{4}$ products were amplified using $P_{2-2,} P_{3-2}$ and $P_{4-2,}$ respectively. The position of the predicted region obtained from amplification using each primer pair is shown in Fig. 1.

The second PCR products were separated on from $1.5 \%$ agarose gel. The DNA band was excised from the gel and purified by Qiaex II protocol (Qiagen) and cloned into a pGEM-T Easy vector. The ligation of the target DNA with the T-vector was achieved with a DNA ligation kit. The resulting ligation solution was used to transform to E. colistrain $\mathrm{DH} 5 \mathrm{a}$ competent cells. Plasmid DNA was extracted from positive cloned and the cDNA insert was amplified using BigDye Terminator Cycle Sequencing kit and sequenced on a DNA Sequencer.

The cloning of full-length cDNA of striped snake-head fish $\mathrm{Mb}$ was performed by using two methods; the 52 - and 32 - rapid amplification of cDNA ends (RACE) PCR methods using the SMART ${ }^{\text {TM RACE }}$ CDNA amplification kit and the typical PCR using gene specific primers for analysis of 52 -end of the fish Mb cDNA. In accordance of

Table 4: Distance between distal His, proximal His and Fe atom in the heme pocket of striped snake-head fish Mb compared with sperm whale and yellowfin tuna Mbs

\begin{tabular}{|c|c|c|c|}
\hline & \multicolumn{3}{|c|}{ 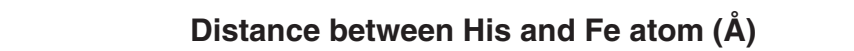 } \\
\hline & Sperm whale & Striped snake-head fish & Yellowfintuna \\
\hline Distal His-Fe distance & 4.5 & 4.36 & 4.40 \\
\hline Proximal His-Fe distance & 2.2 & 5.61 & 5.71 \\
\hline
\end{tabular}


52 - and 32 - RACE PCR reaction, the first-strand CDNAs were synthesized using the following primer pairs; 32 - RACE cDNA synthesis primer (32 -CDS) and SMART II A oligonucleotide for synthesis of 32 - RACE-Ready cDNA and the 52 -RACE cDNA synthesis primer (52 -CDS) and SMART II A oligonucleotide for synthesis of 52 -RACE-Ready cDNA.

To amplify the 52 - and 32 - ends of the stripped-snake head fish Mb cDNA, the gene specific primers; Myg-3R, Myg-3R-nest, Myg-5R and Myg-5R-nest (Table 1) were designed based on an internal sequence of fish Mb cDNA fragment which is obtained from above experiment (Fig. 1). In 32 -RACE, PCR was performed with 32 -RACEReady cDNA as template with primers Myg-3R and universal primer A mix. The PCR was carried out for 30 cycles of denaturation at $93^{\circ} \mathrm{C}$ for $1 \mathrm{~min}$, annealing at $60^{\circ} \mathrm{C}$ for $1 \mathrm{~min}$, and extension at $72^{\circ} \mathrm{C}$ for $1.5 \mathrm{~min}$. Subsequently, the 32 -end RACEPCR products were re-amplified by nested PCR reaction, using primers

1

$493 \mathrm{bp}$

31

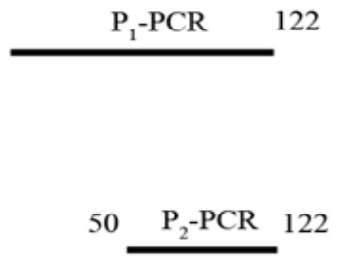

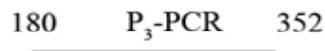

182

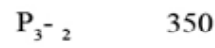

$180 \quad \mathrm{P}_{4}-\mathrm{PCR} \quad 300$

Fig. 1: Positions of predicted regions obtained from amplifications using the designed primer pairs. The top line represents partial sequence of Tetraodon nigroviridis Mb DNA (Accession number: AJ628044). The other lines illustrate predicted regions of DNA obtained from the amplification of striped snake-head fish Mb cDNA using different primer pairs

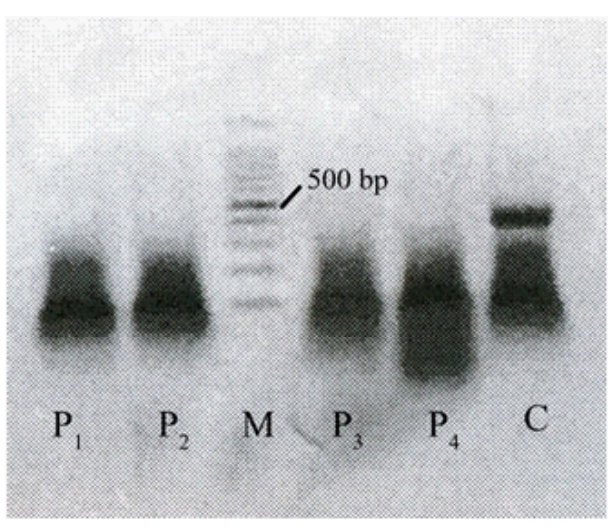

Fig. 2: Agarose gel electrophoresis illustrating the amplified PCR product with different specific primer pairs; Lane $\mathbf{P}_{1}: \mathbf{P}_{1}$ primer pair, Lane $P_{2}: P_{2}$ primer pair, Lane $P_{3}: P_{3}$ primer pair and Lane $P_{4}: P_{4}$ primer pair. Lane $M$ represents Iow DNA mass ladder. Lane $C$ represents the PCR product with $\beta$-actin specific cDNA primers

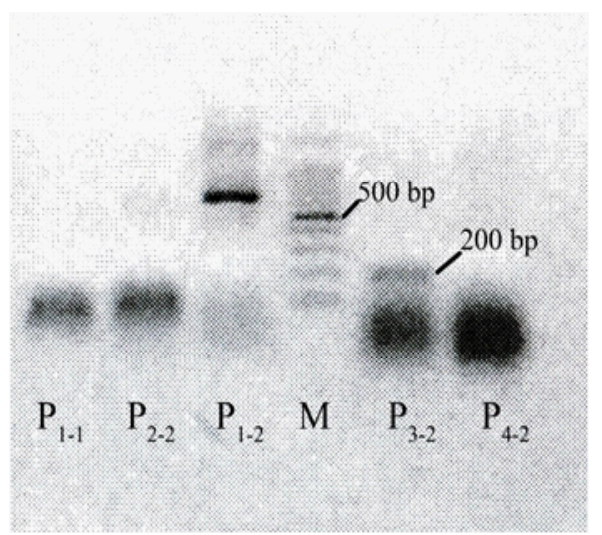

Fig. 3: Agarose gel electrophoresis illustrating the second round PCR products with different specific primer pairs; Lane $\mathbf{P}_{1-1}: \mathbf{P}_{1}$ template with $P_{1-1}$ primer pair, Lane $P_{1-2}: P_{1}$ template with $P_{1-2}$ primer pair, Lane $P_{2-2}: P_{2}$ template with $\mathbf{P}_{2-2}$ primer pair, Lane $\mathbf{P}_{3-2}: \mathbf{P}_{3}$ template with $\mathbf{P}_{3-2}$ primer pair, Lane $\mathbf{P}_{4-2}: \mathbf{P}_{4}$ template with $\mathbf{P}_{4-2}$ primer pair. Lane $M$ represents Iow DNA mass ladder 
Myg_3R-nest and nested universal primer A mix. The nested PCR reaction was carried out with the same condition of 32 -RACE PCR.

For determination of 52 -end of strippedsnake head fish Mb cDNA, the 52 -RACE-Ready cDNA of Mb gene was used as the template and PCR was carried out with primers Myg-5R and universal primer A mix at 30 cycles of denaturation at $93^{\circ} \mathrm{C}$ for $1 \mathrm{~min}$, annealing at $60^{\circ} \mathrm{C}$ for $1 \mathrm{~min}$, and extension at $72^{\circ} \mathrm{C}$ for $1.5 \mathrm{~min}$. Subsequently, the 52 -end RACE PCR products were re-amplified by nested PCR reaction, using primers Myg_5R-nest and nested universal primer A mix with the same condition of 52 -RACE. In addition, the 52 -end of striped-snake head fish Mb cDNA was performed using the typical PCR reaction. The 32 -RACE-Ready cDNA of stripped snake-head $\mathrm{Mb}$ gene obtained from above step was used as the template and the PCR was conducted with Myg_f1 and Myg_r2 primers (Table 1) by the following condition of 32 -RACE. The primary PCR product was subject to nested amplification with Myg_f2 nested and Myg_r2 nested.

Both PCR products of 52 - and 32 -ends cDNA were separated on from $1.5 \%$ agarose gel. The DNA bands was excised from the gel, purified and cloned into a pGEM-T Easy vector. The resulting ligation solution was used to transform to $E$. coli competent cells. Plasmid DNA was extracted from positive cloned and the cDNA insert was amplified using BigDye Terminator Cycle Sequencing kit and sequenced on a DNA Sequencer. A full-length cDNA was constructed by assembly of two cDNA-end clones using Vector NTI Advance 10 software. Based on the obtained nucleotide sequence of stripped snake-head fish Mb cDNA, the amino acid sequence was deduced using Vector NTI Advance 10 software and Bioedit program.

\section{Molecular modeling of the fish $\mathrm{Mb}$}

The Mb structure of the striped snake-head fish was generated with SWISS-MODEL Workspace, a web-based environment for protein structure homology modeling using the X-Ray structure of blackfin tuna Mb (Protein Data Bank (PDB) code $2 \mathrm{nrl})^{36}$ as a template with a sequence identity of $73.24 \%$. The SWISS-MODEL method was used in combination with the DeepView 4.0.4 program and Vector NTI Advance 10 software.

\section{Phylogenetic comparison of Mb sequence}

Phylogenetic tree was constructed based on the amino acid sequence of striped snakehead fish $\mathrm{Mb}$ and the other species. The amino acid sequence was used to conduct a search of Protein knowledgebase (UniprotKB; http://www. uniprot.org) with the BLASTW algorithm. The Mb from some fishes, mammalians, avians and reptiles were selected for construction of unrooted tree by CLUSTALW, PHYLIP and Tree view program, using chicken (Gallus gallusdomesticus) as the out group. The analysis included $\mathrm{Mb}$ sequences from fish species: yellowfin tuna (Thunnus albacore), unicorn ice fish (Channichthys rhinoceratus), Atlantic blue marlin (Makaira nigricans), Atlantic chub mackerel (Scomber colias), port jackson shark (Heterodontus portusjacksoni), tope shark (Galeorhinus galeus), zebrafish (Danio rario), goldfish (Carassius auratus) and common carp (Cyprinus carpio), mammalian species: sperm whale (Physeter macrophalus), bridled dolphin (Stenella attenuate), grey seal (Halichoerus grypus), Asiatic elephant (Elephas maximas), water buffalo (Babalus bubalis), horse (Equus caballus), weasel lemur (Lepilemur mustelinus) and emperor penguin (Aptenodytes forsteri), avian species: whiskered auklet (Aethia pygmaea), spotbill duck (Anas poecilorhynca), shag phalacroco (Phalacroco raxaristoteris) and ostrich (Struthio camelus), reptile species: green sea turtle (Chelonia mydas), map turtle (Grapemus geographica), logger head sea turtle (Caretta caretta) and lace monitor (Varanus varias).

\section{Determination of sequence similarity}

The amino acid sequence of striped snakehead fish $\mathrm{Mb}$ was used to determine the homology with Mbs from other fishes (yellowfin tuna Thunnus albacore, blue marlin Makaira nigricans, chub mackerel Scomber colias, common carp Cyprinus carpio, goldfish Carasssius anratus and zebrafish Danio rerio) using Bioedit sequence alignment program and Vector NTI Advance 10 software and Bioedit program.

\section{RESULTS AND DISCUSSION}

\section{The deduced amino acid sequence}

Total RNA was extracted from frozen striped snake-head fish muscle using TRIZOL method. cDNA was then synthesized and amplified using One-step 
reversed transcription polymerase chain reaction (One-step RT-PCR). The first PCR products of fish $\mathrm{Mb}$ cDNA resulting from One-step PCR using the 4 pairs of primers including $P_{1}, P_{2}, P_{3}$ and $P_{4}$ under the conditions described are shown in Fig. 2. There was no evidence of an amplified PCR band in all of $\mathrm{P}_{1}, \mathrm{P}_{2}, \mathrm{P}_{3}$ and $\mathrm{P}_{4}$ samples. While the PCR product which used â-actin specific cDNA primers as the reference control could be observed. Therefore, all first PCR products were re-amplified by the same PCR conditions using the predicted internal primer pairs to amplify the specific DNA fragment located within the first PCR products and to provide better amplification of the desired DNA.

The second round for PCR products which were analyzed on agarose gel are shown in Fig. 3. The PCR products of $P_{1}$ with internal primer pairs of $P_{1-1}$ and $P_{1-2}$ were referred as $P_{1-1}$ and $P_{1-2}$, respectively. The PCR products of $\mathrm{P}_{2}, \mathrm{P}_{3}$ or $\mathrm{P}_{4}$ with internal primer pairs of $\mathrm{P}_{2-2}, \mathrm{P}_{3-2}$ or $\mathrm{P}_{4-2}$ were also referred as $P_{2-2}, P_{3-2}$ and $P_{4-2}$, respectively. Gel

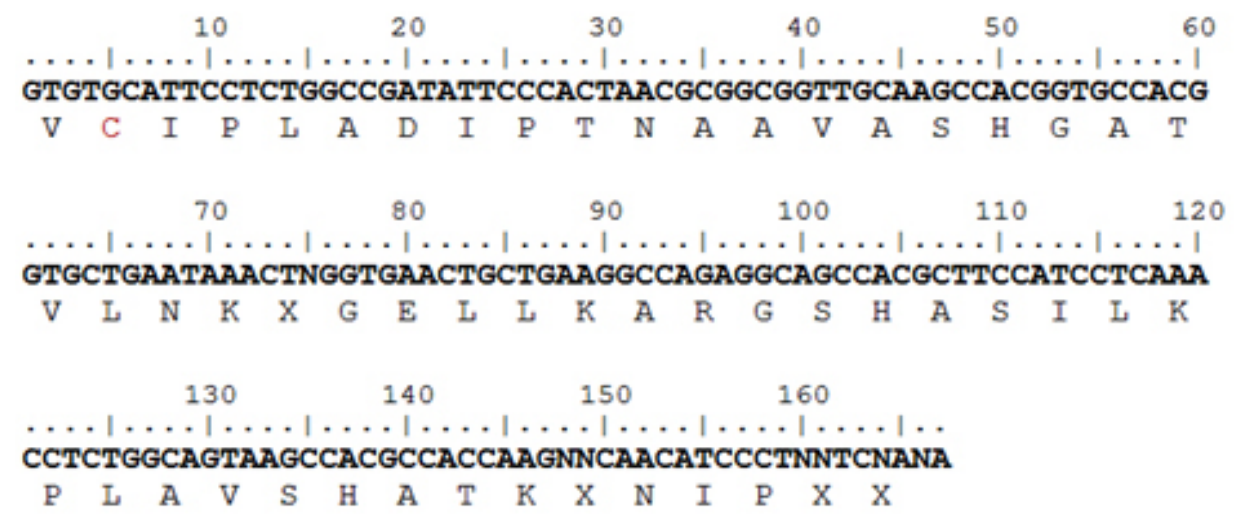

Fig. 4: Nucleotide sequence and deduced amino acid sequence of 167 bp cDNA encoding the striped snake-head fish Mb

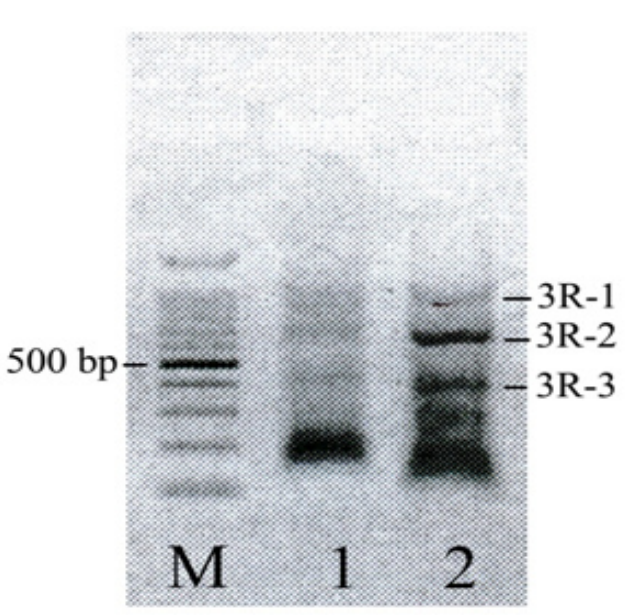

Fig. 5: Agarose gel electrophoresis illustrating the 3' RACE amplification of Mb cDNA; Lane M: Iow DNA ladder, Lane 1, 2; 3' RACE product and 3' RACE-nested product, respectively. The three products of $3^{\prime}$ RACE are 3R-1, 3R-2 and 3R-3, whose sizes are 1500, 700 and 400 bp, respectivetly analysis of the $\mathrm{P}_{3-2} \mathrm{PCR}$ product showed the band at around $200 \mathrm{bp}$ corresponding to the predicted region obtained from DNA sequence of $T$. nigroviridis $\mathrm{Mb}$ DNA. Thus, the $\mathrm{P}_{3-2}$ desired band was excised from agarose gel. The excised cDNA band was extracted and purified. The cDNA fragment was ligated and cloned, and then subjected to DNA sequencing using the dideoxy chain termination method. A cDNA insert had a length of $167 \mathrm{bp}$ (Fig. 4) and encoded a protein of 51 amino acid residues except for 4 amino acid residues could not be uncoded. The deduced amino acids sequence was found to be consistent with Mbs of some fishes.

\section{Rapid amplification of cDNA ends and nucleotide} sequence analysis

The complete Mb cDNA of the striped snakehead fish was determined by rapid amplification of cDNA ends (RACE) PCR. The obtained nucleotide fragment of $167 \mathrm{bp}$ cDNA ( $\mathrm{P}_{3-2}$ PCR product) was used to design gene specific primers (Myg-3R, Myg3R- nested, Myg-5R, Myg-5R-nested). 3'-RACE- 
Ready cDNA was synthesized from mRNA using RT-PCR with oligo(dT) primer and 32 -CDS and amplified using Myg-3R and universal primer A mix. The subsequent PCR using a nested gene specific primer (Myg-3R-nest) and the nested universal primer mix results in the specific amplification cDNA ends. The 3'RACE products show three bands on agarose gel at around 1500,700 and 400 referred as 3R-1, 3R-2 and 3R-3, respectively (Fig. 5). All three bands were excised from the gel and the 3'RACE products were extracted and purified. The cDNA fragment was ligated to PGEM-T Easy vector, then cloned in E. coli strain DH5a competent cells and subjected to DNA sequencing. The result showed that the 3R-2 and 3R-3 fragments had nucleotide length of 450 and 696 bp, respectively (Fig. 6 and 7) while the $3 R-1$ could not be analyzed its sequence.

Interestingly, the $696 \mathrm{bp}$ fragment contains two stop codon and duplicated poly (A) site (ATAAAA) which caused by $\mathrm{Mb}$ gene mutation.

According to 5' RACE amplification, no bands were observed in 5' RACE reaction because the 5'-RACE-Ready cDNA could not be synthesized. The typical PCR reaction was used for amplification of 5 'cDNA ends using the 32 -RACE-Ready cDNA as the template with primers Myg_f1 and Myg_r2. The obtained PCR products were subject to the nested PCR using with Myg_r2-nested and the mix of two primers; Myg_f1-nested and Myg_f1-nested. The products showed single band at around 300 bp on agarose gel (Fig. 8). The obtained nucleotide sequence of 5' RACE product revealed 321 bp (Fig. 9).

The complete nucleotide sequence of the striped snake-head fish Mb was constructed by joining overlapping region of the 5 ' ends and $3^{\prime}$ ends cDNA and two lengths of nucleotide sequences were obtained (Fig. 10). Sequence analysis showed two sequences with different lengths in $3^{\prime}$ untranslated regions 3' UTR, referred as Mbl gene and Mbll gene. Both sequences revealed that the 5 'untranslated region ( $5^{\prime}$ UTR) of both $\mathrm{Mbl}$ gene and $\mathrm{Mb}$ II gene contained 30 nucleotides and the amino acid-coding region of both Mbs contained 450 nucleotides. However, Mbl gene and Mbll gene showed the different length of $3^{\prime}$ UTR with 164 nucleotides and 410 nucleotides, respectively. In accordance to amino acid coding region, both genes encoded protein with 145 amino acid residues. Both cDNA sequences of the striped snake-head $\mathrm{Mb}$ and its deduced amino acid sequence are shown in Fig. 11 and 12 .

In addition to the sequence identity in the overlapped region, both $\mathrm{Mbl}$ and Mbll showed a high conservation within the region except for some uncoded residues, confirming that $\mathrm{Mbl}$ gene and Mbll gene was obtained from the correct cDNA clones. However, there is only one different coded residue in the overlap region between $5^{\prime}$ ends product and 3' RACE fragments of both Mb genes. The coded residue is Lys $(\mathrm{K})$ at nucleotide position $323-325$ in $5^{\prime}$ RACE fragment (Fig. 9) while, both 321 bp and 696 bp of 3' RACE fragments at nucleotide position 118120 were Ser (S) instead. The corrected residues at this position within the overlapped region should be Ser because both two nucleotide sequences of 3' RACE fragments was sequenced separately but both of them revealed Ser.

As mentioned above, $\mathrm{Mb}$ of the stripped snake-head fish has two types; Mbl gene and Mbll gene. The amino acid coding region of both $\mathrm{Mbl}$ and Mbll DNA sequences have an equal length. But both sequences are different in the lengths of the 3' UTR. Moreover, the $3^{\prime}$ UTR of Mb II contained two stop codons and duplicated poly (A) site (Fig. 12). The two types of the fish $\mathrm{Mb}$ and the presence of two stop codons and duplicated poly (A) in 3' UTR of $\mathrm{Mb}$ II might be explained to two possible distinct mechanisms. Firstly, we suggest that the fish $\mathrm{Mb}$ may consist of several components, some of which are self-associated into two polymeric globins. Secondly, it is noted by which the gene mutation or gene duplication of the protein occurred. This gene duplication is possibly found in $\mathrm{Mb}$ of some heat tolerant fishes which is known to possess two $\mathrm{Mb}$ paralogs ${ }^{37,38}$. Gene duplication is considered to play very important roles in the organism evolution ${ }^{39,40}$. If a gene is duplicated, the selective constraint becomes less for the extra copy, and it may have a different function, while the original function of the genes is kept in the other copy. Thus, gene duplication with subsequent diversification is one of the simplest ways to acquire a new function and is thought to employ many times during evolution. In case of 
globin family containing several genes, it is coded for different types of $\mathrm{Mb}$ molecule in vertebrates ${ }^{41}$. The different polypeptides that make up Mb appear to have evolved by gene duplication from a single, original Mb-like gene. Presently in the hypoxiatolerant common carp and goldfish, there are several types of Mb molecules produced that are essential for development and survival of fish because they are produced specifically in different tissues and at different stages of the development ${ }^{37,38}$. From the results of both purification and characterization of the striped snake-head fish $\mathrm{Mb}$, it might be concluded that the fish composed of at least two types of Mbs which may act different functions. This can be concluded for the tolerant behavior of this fish under hypoxia.
Determination of primary structure of the fish Mb

The primary structure of this fish $\mathrm{Mb}$ which is deduced from two lengths of Mb DNA sequence, referred as $\mathrm{Mbl}$ and Mbll, contains 145 amino acid residues as shown in Fig. 13. Both $\mathrm{Mbl}$ and Mbll have almost similar amino acid sequence except in the position of 114 and 137. At these positions, there are replacements between Lys and Asn residues among these $\mathrm{Mb}$ structures. By comparison with $\mathrm{LC}$ MS/MS results (unpublished data), there is only one incorrect amino acid residue in an assignment of the sequence at position of 117 . Thus, the LC-MS/MS with tryptic digestion de novo sequencing is reliable method and the deduced amino acid sequence of the $\mathrm{Mb}$ is correct.

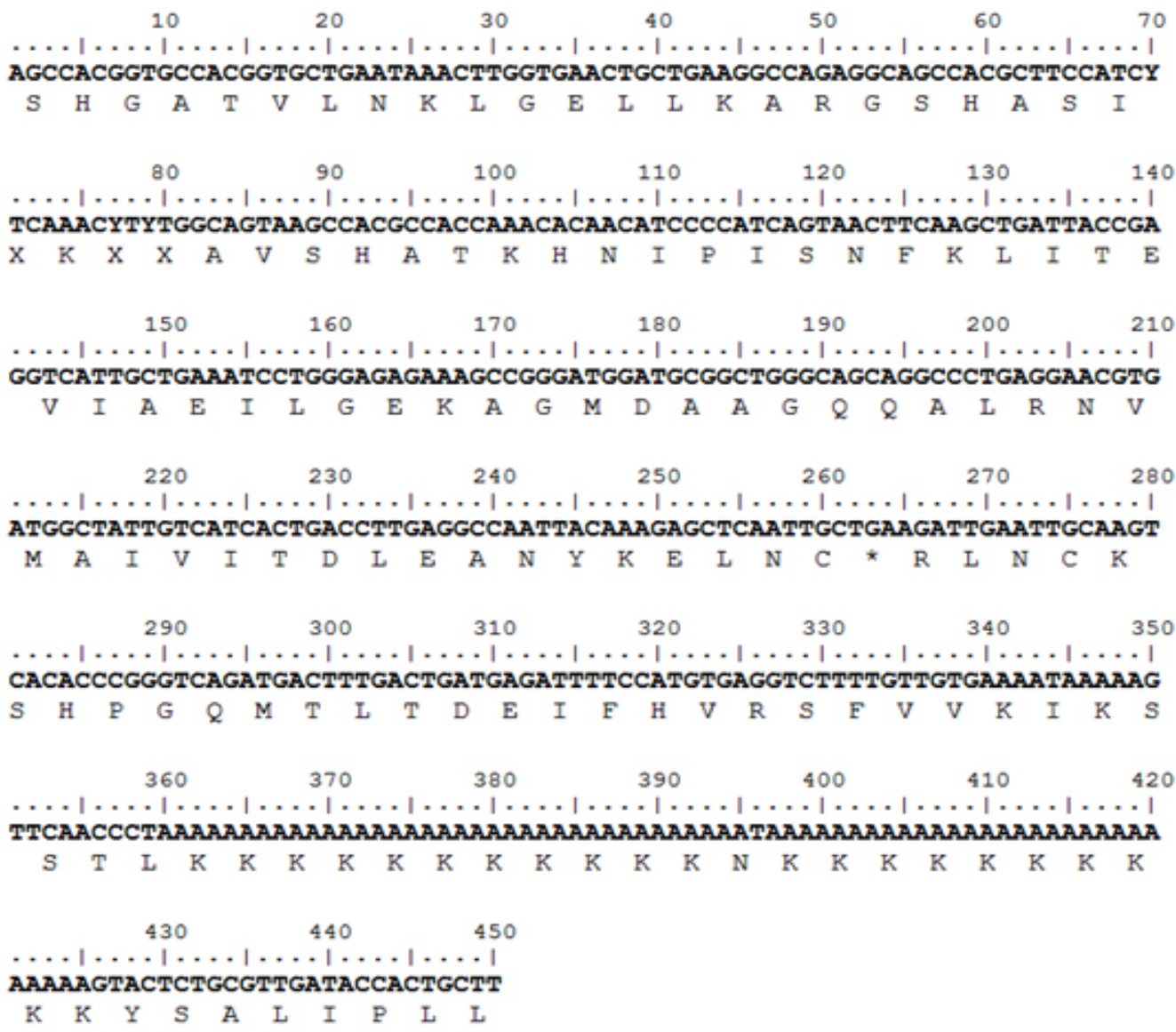

Fig. 6: Nucleotide sequence and deduced amino acid sequence of 450 bp of $3^{\prime}$ RACE product encoding the striped snake-head fish Mb 
Since trypsin is specific to C-terminal side of Lys and Arg, the position of 117 for both $\mathrm{Mbl}$ and Mbll should be Arg. Interestingly, at this position was replaced by Met instead of Arg. This result could indicate that the fish $\mathrm{Mb}$ was possibly expressed as two isoforms. Moreover, this information is useful that the $\mathrm{Mb}$ may consist of several components, not only two types of the globin.

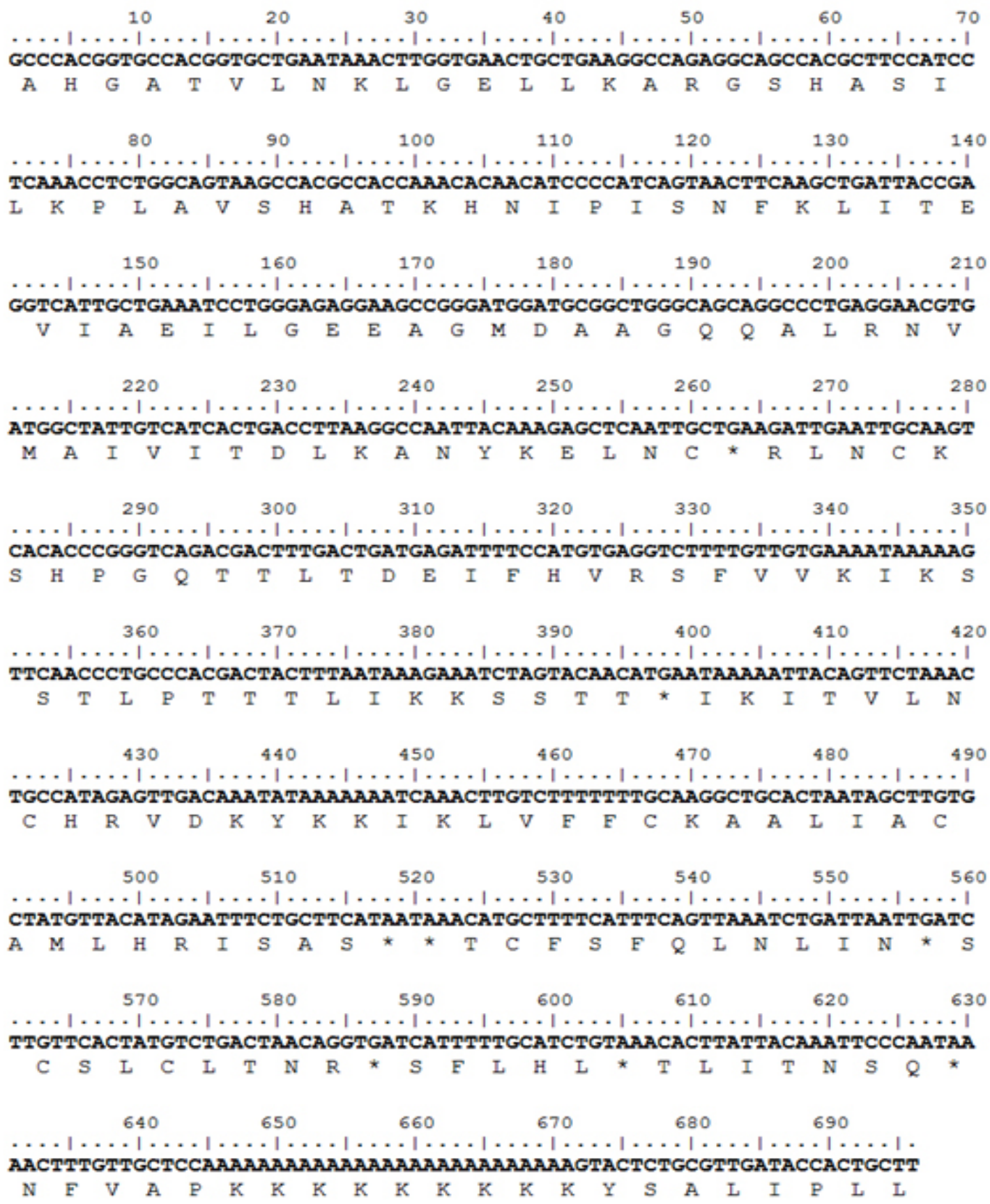

Fig. 7: Nucleotide sequence and deduced amino acid sequence of 696 bp of $3^{\prime}$ RACE product encoding the striped snake-head fish Mb 
Interestingly, the fish Mb structure contained two cysteine residues at position 14 and 145. While the $\mathrm{Mb}$ of other fishes contained only one cysteine residue. The cysteine leads to disulfide bridge

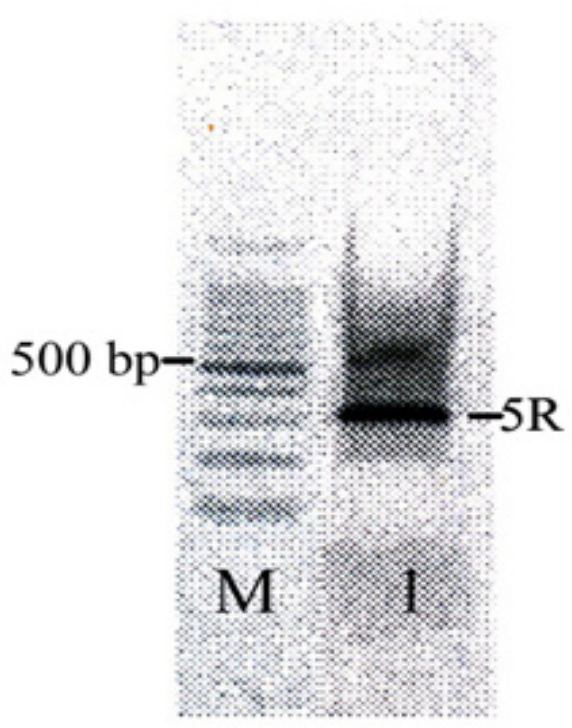

Fig. 8: Agarose gel electrophoresis illustrating the 5' RACE amplification of Mb cDNA; Lane M: Iow DNA ladder, Lane 1; 5' RACE nested product revealed around $300 \mathrm{bp}$ formation in molecule which plays very important role in stabilization of protein structure in high level. In the case of cysteine that is not involved in the disulfide bridge formation can also help stabilize á-helix. Therefore, this Mb structure tends to have higher stability than other fishes. This suggestion may support the living habitat of this fish in tolerance to low oxygen demand. Moreover, because the fish $\mathrm{Mb}$ contains two cysteine residues to form disulfide bond, it can covalently anchor within the tertiary structure to form a functional multimeric protein. This reason may confirm that the fish $\mathrm{Mb}$ is a novel $\mathrm{Mb}$ which present as at least two-type of Mb components. Each component might either be associated with other proteins or self-associated into any isomeric protein.

Table 3 showed the amino acid composition of the fish $\mathrm{Mbl}$ and Mbll. The high content of the acid residues is hydrophobic amino acids including leucine, isoleucine and valine. The molecular mass of the fish $\mathrm{Mb}$ which calculated from amino acid residue was found to be $15,700 \mathrm{Da}$ (SDS-PAGE). This theoretical molecular mass is higher than that of MALDI-TOF-MS (15,597.68 Da).

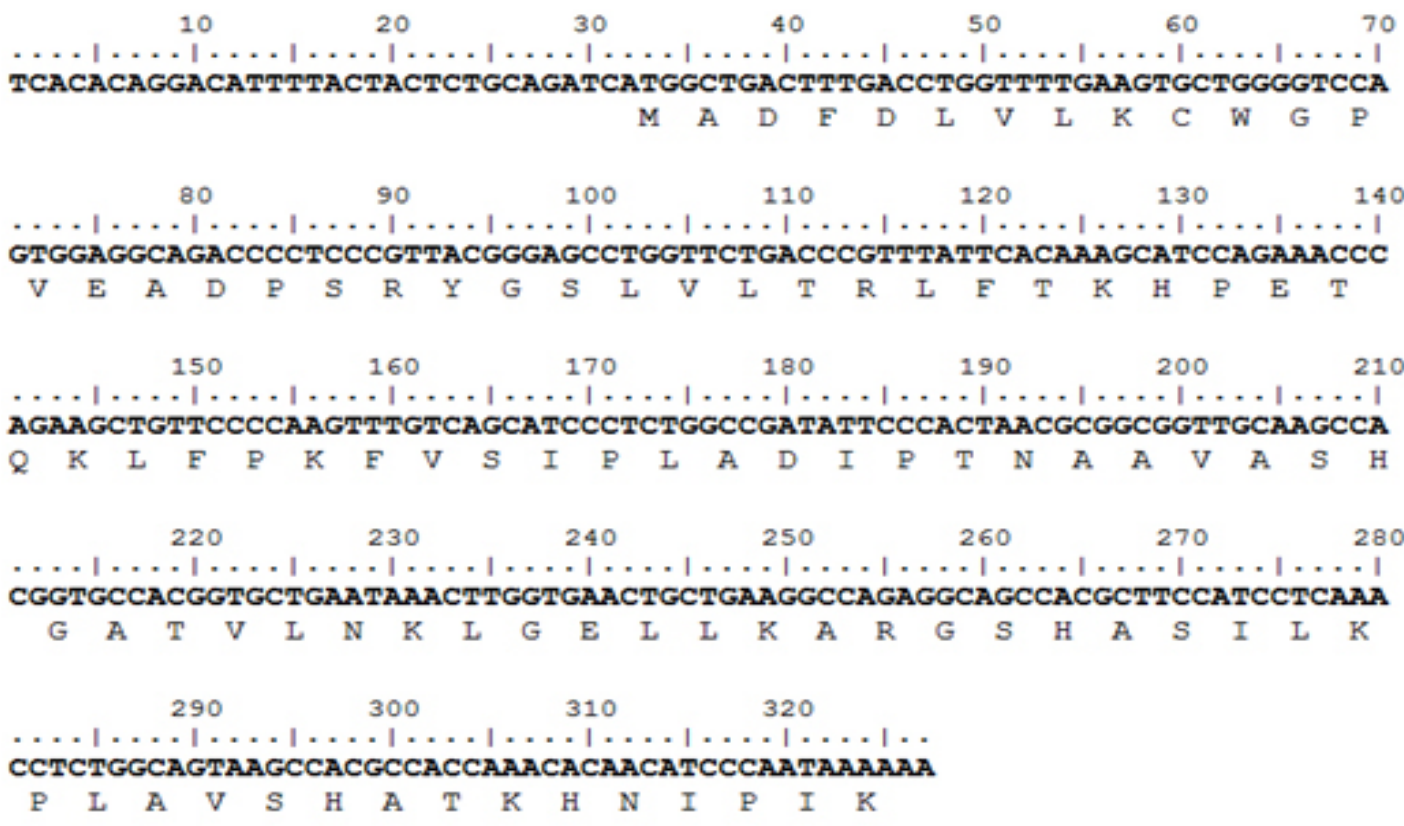

Fig. 9: Nucleotide sequence and deduced amino acid sequence of 321 bp of $5^{\prime}$ RACE product encoding the striped snake head fish $\mathrm{Mb}$ 


\section{$\mathrm{Mb} \mathrm{cDNA}(160 \mathrm{bp})$}

5'RACE (320bp)

3'RACE_1 (450bp)

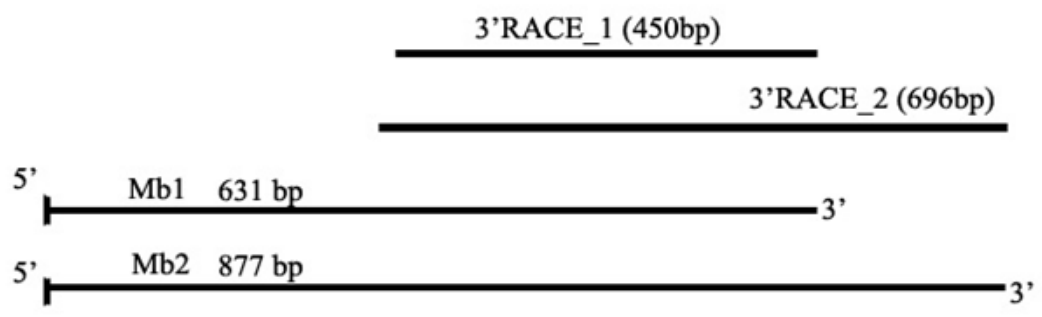

Fig. 10: Schematic of the construction of a full-length cDNA of the striped snake- head fish Mb

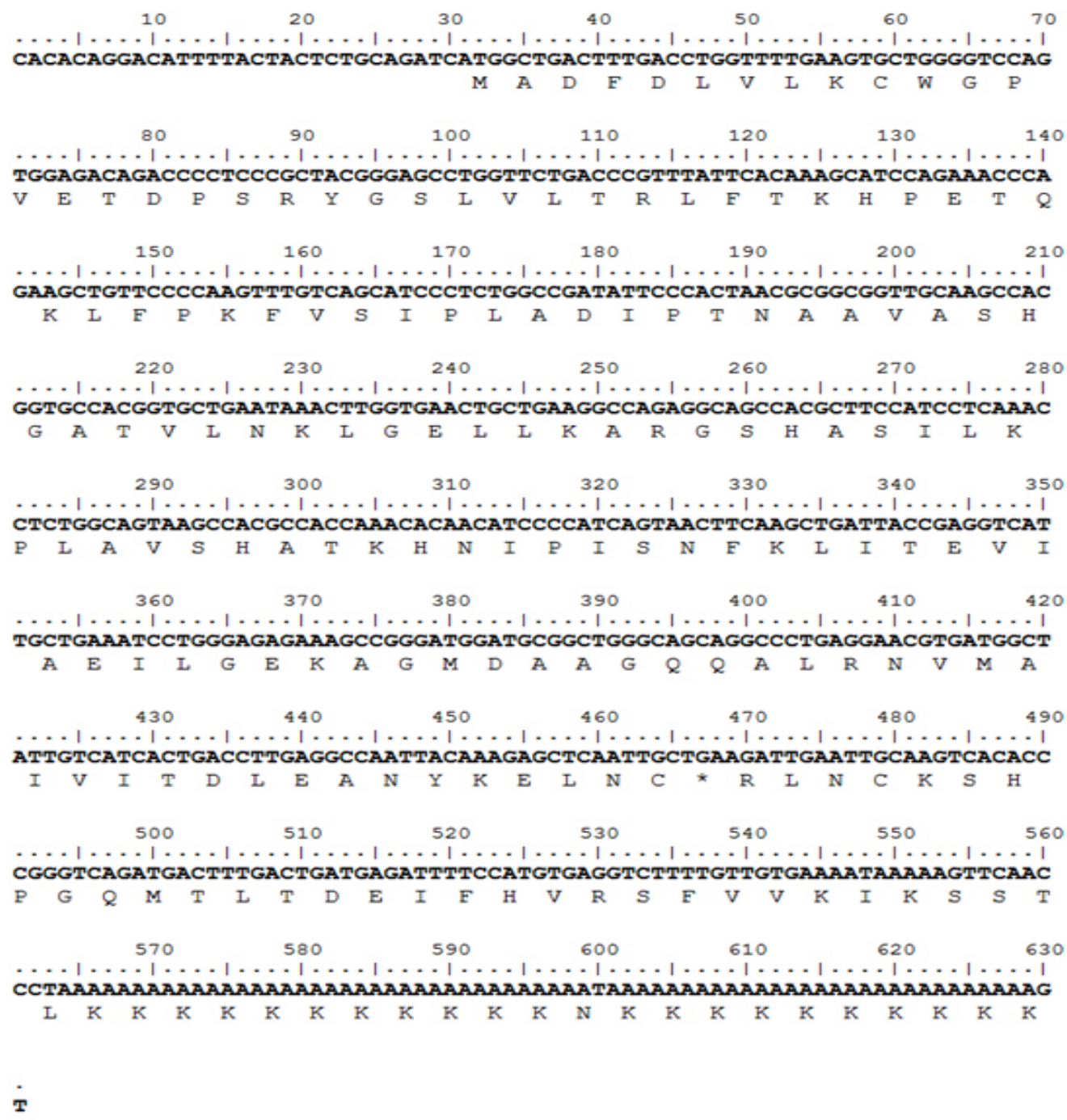

Fig. 11: Complete nucleotide sequence with 164 bp non-coding region and the deduced amino acid sequence of the striped snake head fish Mb (Mbll) 


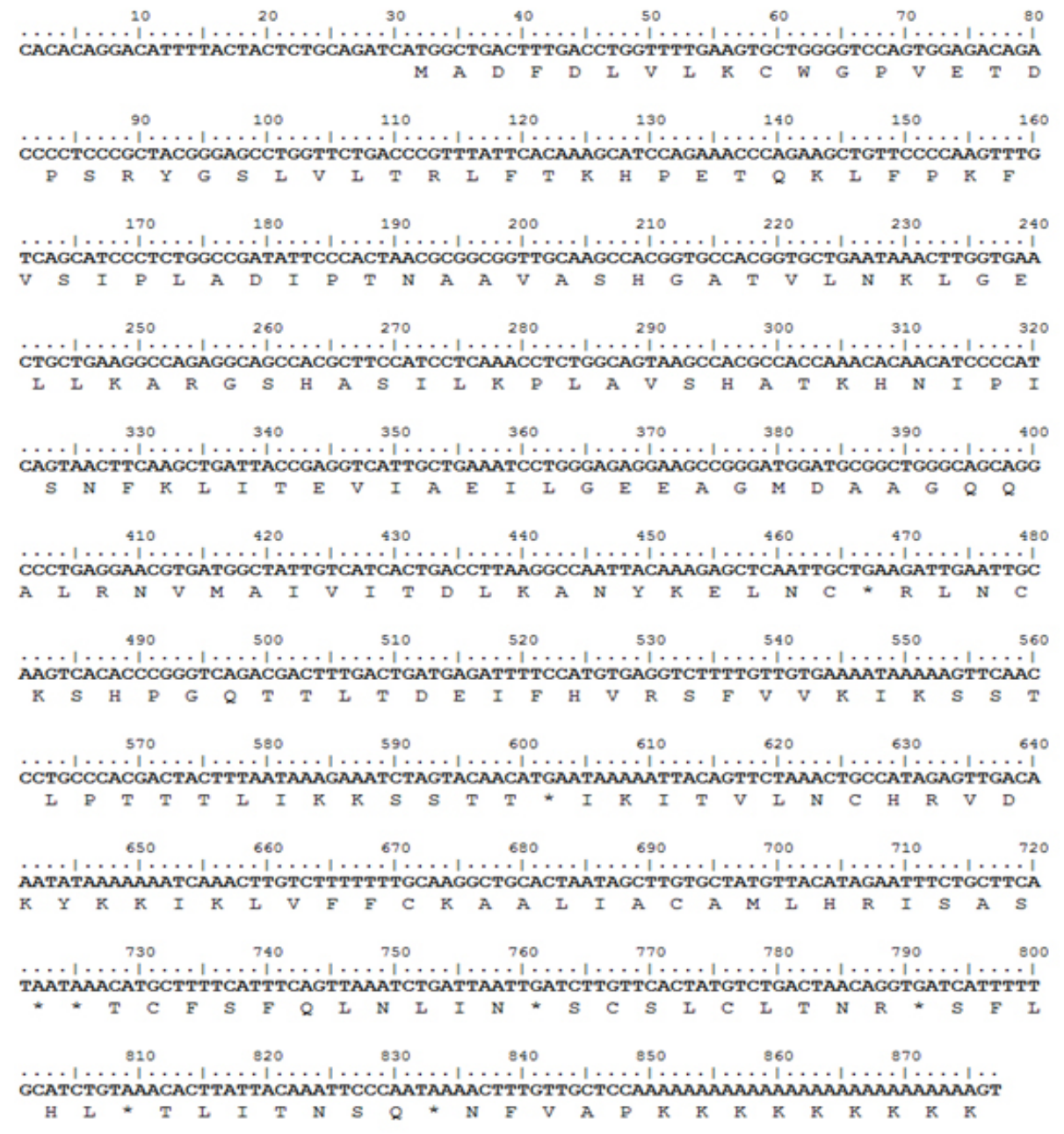

Fig. 12: Complete nucleotide sequence with 410 bp non-coding region and the deduced amino acid sequence of the striped snake head fish $\mathrm{Mb}(\mathrm{Mbl})$

$\begin{array}{rrrrr}10 & 20 & 30 & 40 & 50\end{array}$

$\begin{array}{lccccc} & & 10 & 20 & 30 & 40\end{array}$

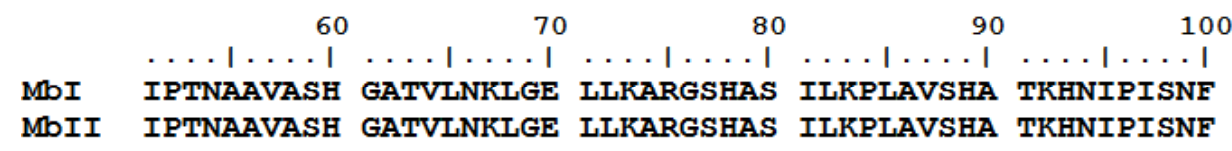

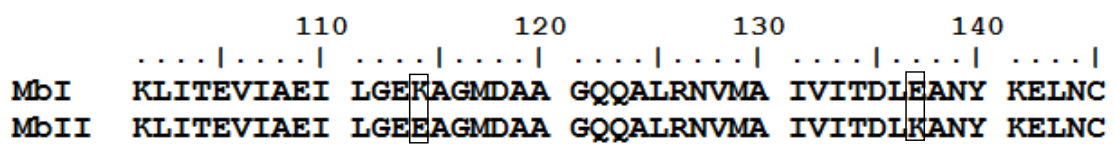

Fig. 13: Deduced amino acid sequences of the striped snake-head fish Mb. The different residues among two sequences are boxed 
The theoretical isoelectric point $(\mathrm{pl})$ of the fish $\mathrm{Mb}$ was found to be 7.82. This pl value is close to that of horse $\mathrm{Mb}(7.65)$ more than that of Asian swamp eel $\mathrm{Mb}$, the tolerant freshwater fish, which has previously been studied (6.40 and $7.12^{42}$. By comparison, the $\mathrm{pl}$ value of the fish $\mathrm{Mb}$ is found higher than those of some fish species, for examples, pl values of mackerel and sardine Mbs are 5.8 and 5.9 , respectively ${ }^{43}$ and $\mathrm{pl}$ of carp $\mathrm{Mb}$ is $5.3^{44}$. It could be suggested that the striped snake-head fish $\mathrm{Mb}$ may have some structural characteristics similar to $\mathrm{Mb}$ of other vertebrate species.

Phylogenetic tree of the deduced amino acid sequence

The alignments for primary structures of the striped snake-head fish $\mathrm{Mbl}$ and Mbll with some of fish Mbs are shown in Fig. 14. The sequences of the fish $\mathrm{Mb}$ are slightly two residues shorter than those of the other fishes. At the position 59 which is in the closed neighbor of the distal histidine (His60), the other fish Mbs showed homologous amino acid residues (Ala59). An Arg at position 59 of other fish Mbs was replaced by Ser in the striped snake-head $\mathrm{Mb}$. Because the Ser structure contains hydroxyl group, it might be suggested that this position can help the distal histidine to serve strong stability for the binding of the ferrous iron in heme to oxygen molecule.

The primary structure of the striped snakehead fish Mbl was identical to that of yellowfin tuna, Atlantic blue marlin, chub mackerel, goldfish, carp and zebrafish with the amino acid sequence identity of $70.74,66.67,64.62,63.26,60.54$ and $57.14 \%$, respectively. On the other hand, the striped snake-

10

20

30

40

50

T.albacore

M.nigricans

S.colias

C. auratus

C. carpio

D. rerio

O.striatusI

O.striatusII

T.albacore

M.nigricans

S.colias

C. auratus

C. carpio

D. rerio

O.striatusI

O.striatusII

T.albacore

M.nigricans

S.colias

C. auratus

C. carpio

D. rerio

O.striatusI

O.striatusII

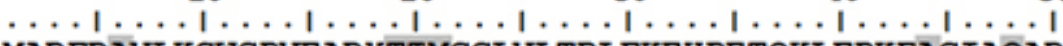
MADFDAVLKCWGPVEADYTTMGGLVLTRLFKEHPETQKLF PKFAGIAQAD MADFEMVLKHWGPVEADYATHGNLVLTRLFTEHPETQKLFPKFAGIAKAD MADFDAVLKFWGPVEADYDK IGNMVLTRLFTEHPDTQKLF PKFAGIGLGD MADHELVLKCWGVVEADFEGTGGEVLTRLFKQHPETQKLFPKFVGIAQSD MHDAELVLKCWGGVEADFEGTGGEVLTRLFKQHPETQKLFPKFVGIASNE MADHDLVLKCWGAVEADYAANGGEVINRLFKEYPDTLKLFPKFSGISQGD MADFDLVLKCWGPVETDPSRYGSLVLTRLFTKHPETQKLFPKFVSIPLAD MADFDLVLKCWGPVETDPSRYGSLVLTRLFTKHPETQKLFPKFVSI PLAD

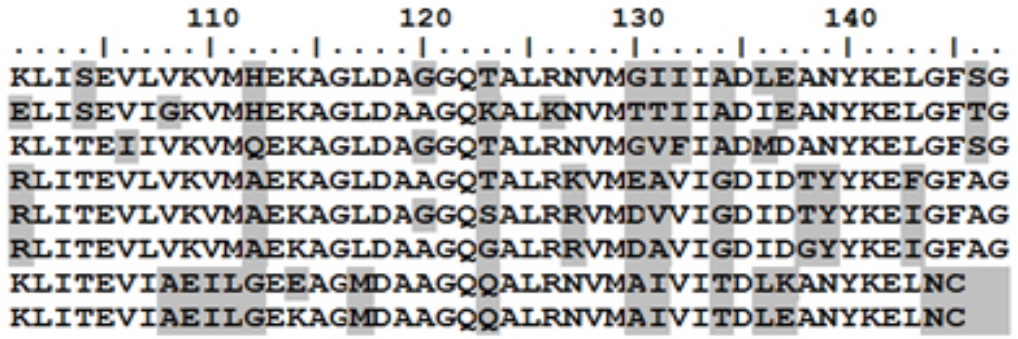

Fig. 14: Alignment of the fish Mbl and Mbll with some of freshwater fishes; common carp, zebrafish and goldfish, marine fishes; yellowfin tuna, blue marline and chub mackerel. Gray boxes indicate the difference in amino acid residues among these fish Mbs 
head Mbll gave higher homologous amino acids to other Mbs than its Mbl with the amino acid sequence identity of $72.10,68.02,65.31,63.94,61.22$ and $57.82 \%$, since the amino acid residues at position of 114 and 137 of Mbll amino acid sequence are identical to the other Mbs. Whereas these residues at the two positions of 114 and 137 in the Mbl sequence are different. Interestingly, the amino acid sequences of this fish Mb showed higher homologous identity to those of marine fish than freshwater fish. These data indicated that this fish species is quite different from another typical freshwater fish.

An evolutionary tree which was drawn based on amino acid sequences of the striped snake-head fish $\mathrm{Mb}$ is depicted in Fig. 15. An

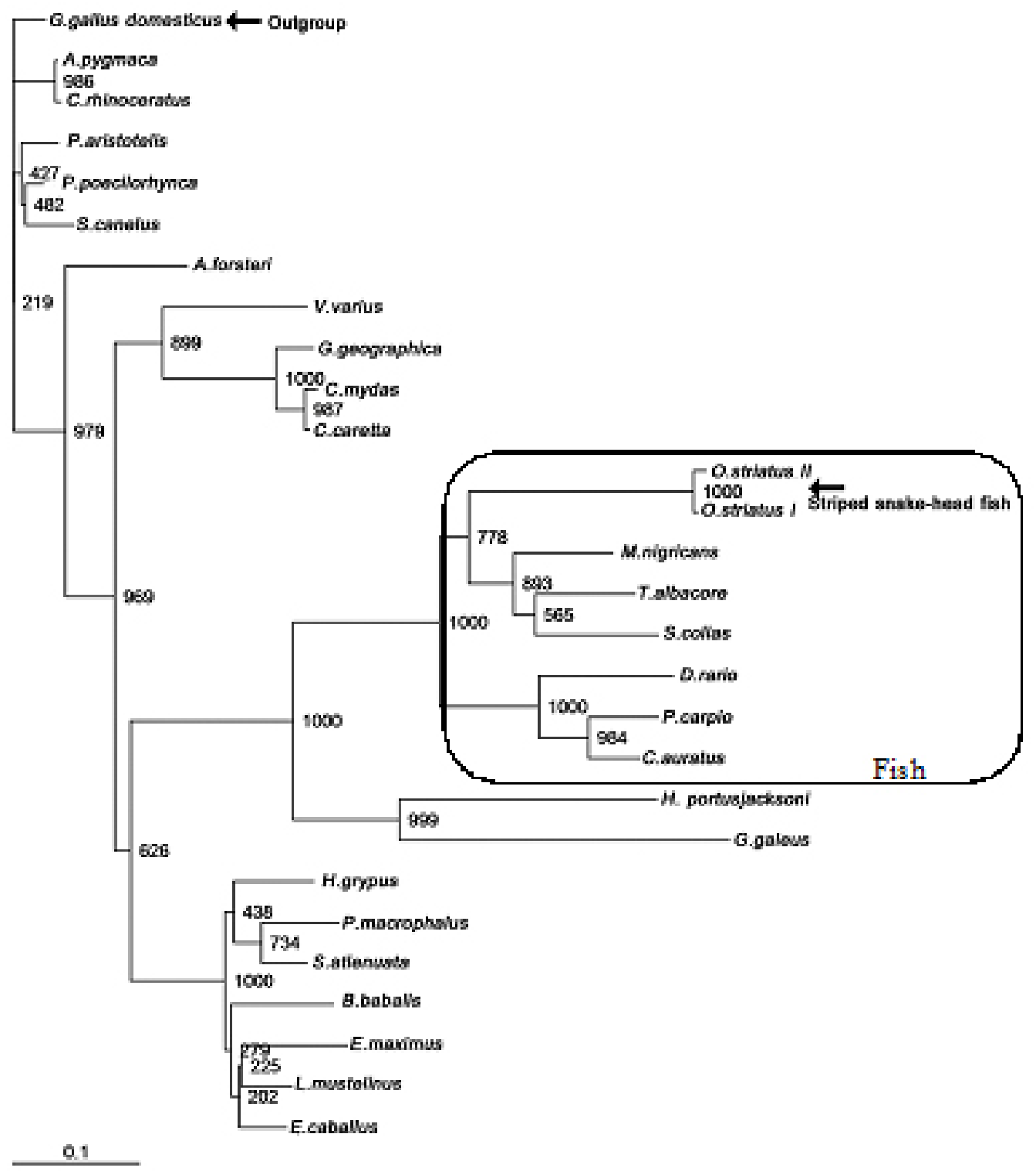

Fig. 15: An unrooted tree phylogeny of Mb from the striped snake-head fish (O. striatus) based on amino acid sequences of Mbs was done by using CLUSTALW and Tree view program, using Phalacrocoracidae as the out group. The numbers of branch are the confidence levels calculated from 1000 replicate analyses 
unrooted phylogenic tree was constructed to get simple comparisons of the sequences of the Mbs from various species including fishes, mammals, reptiles and avians. Mb of fish species branched into two groups in the phylogenetic tree; marine fish and freshwater fish. Those of group formed a cluster and found to be closely related to each other. Surprisingly, the analysis presented here is consistent with an interpretation that the striped snake-head fish $\mathrm{Mbl}$ and Mbll, the freshwater fish, is not fixed at the same cluster of either marine fishes or freshwater fishes but it is still a member of the same clad. The striped snake-head fish Mb was found to be a close evolutionary with Atlantic blue marlin, yellowfin tuna and chub mackerel rather than some heat tolerant freshwater fish such as common carp. In addition,

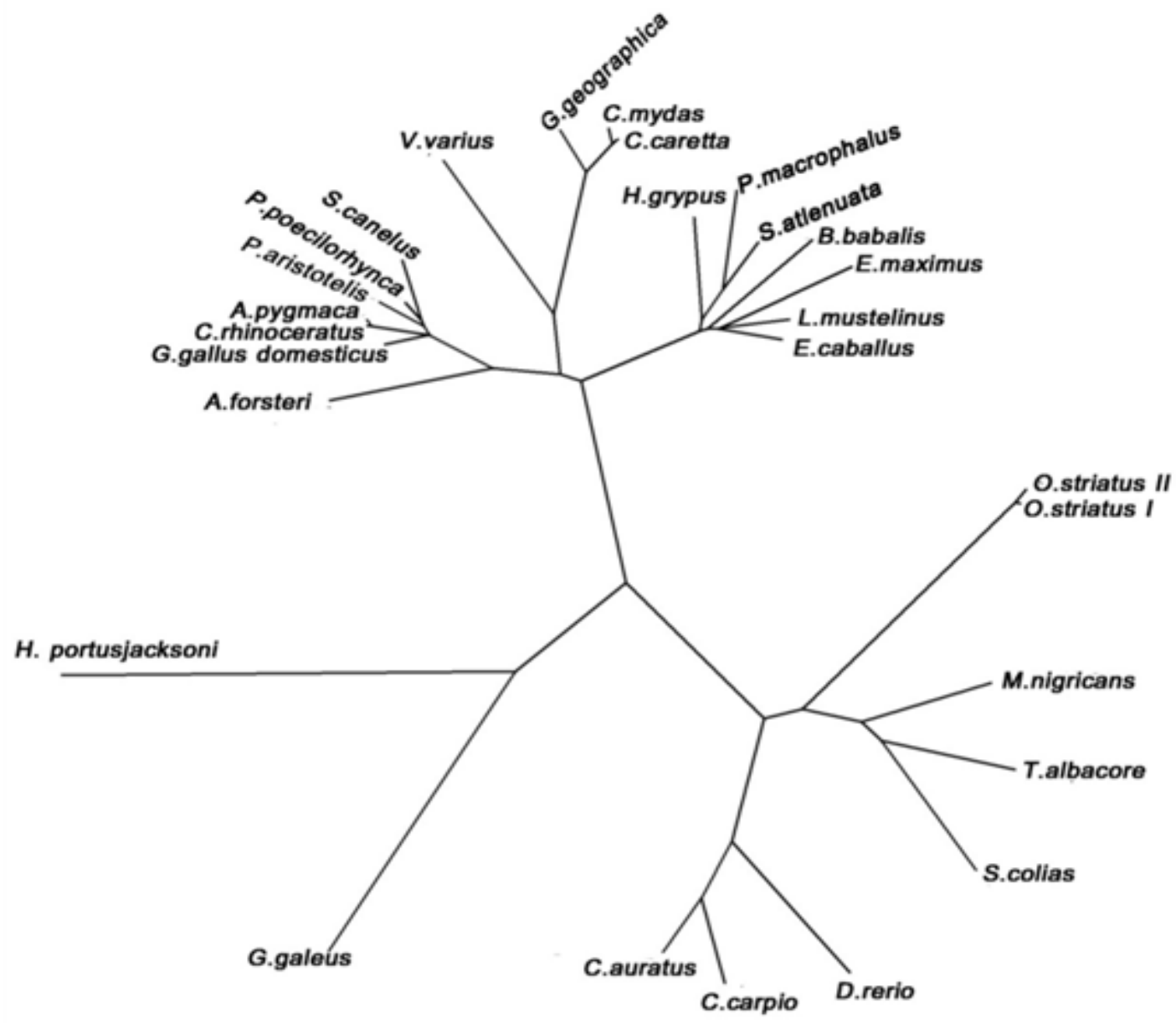

Fig. 16: Phylogenic tree of Mbs from the striped snake-head fish ( 0 . striatus) based on amino acid sequences of Mbs by the neighbor-joining method 
the phylogenetic tree was also constructed by the neighbor-joining method using the PHYLIP program. The neighbor-joining tree of the striped snake-head fish $\mathrm{Mb}$ showed the similar evolution as a result of the unrooted phylogenetic tree (Fig. 16). The striped snake-head fish $\mathrm{Mb}$ is found in the same group of the fish species but locates in the vicinity of marine fishes.
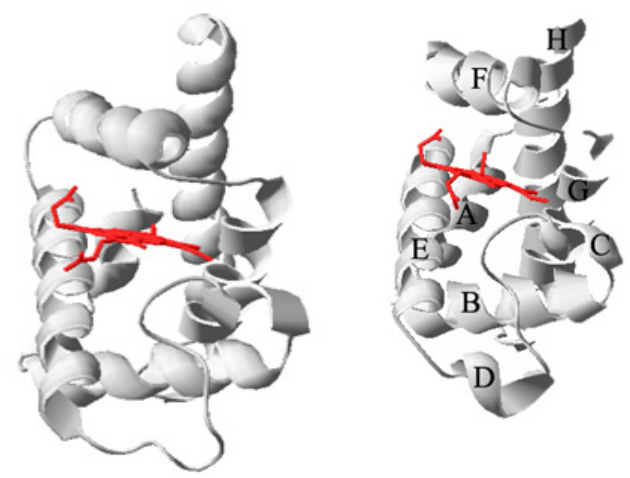

Fig. 17: Ribbon structure of (a) striped snakehead Mb (b) sperm whale Mb
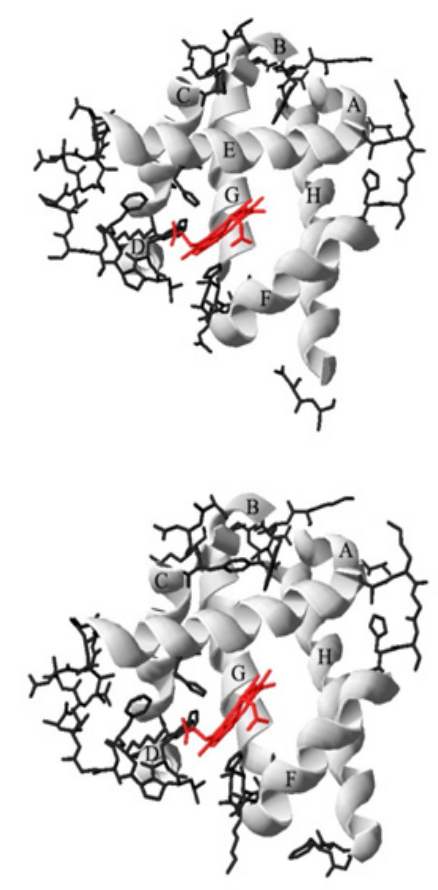

Fig. 18: The $0.91 \AA$ A resolution ribbon structure showing amino acid residues not in helices and its side chain of (a) striped snake-head Mb (b) yellowfin tuna Mb
Atlantic blue marlin, chub mackerel and yellowfin tuna are probably one of the most active and high energetic fish. This behavior correlates with $\mathrm{Mb}$ concentration in their muscle ${ }^{45}$. Moreover, these fish can maintain maximal function of the oxidative locomotor muscles when the water temperature changes to be high ${ }^{46}$. This is also supported by high levels of Mb found in these fishes which serve to maintain contractility and facilitate an oxygen diffusion period rather than keep oxygen storing during low ambient oxygen. From phylogeny results, it might be implied that one role of either Mbl or Mbll in the stripped snake-head fish muscle is the oxygen carrier as same as Atlantic blue marlin, yellowfin tuna and mackerel.

\section{Three-dimensional structure of the fish $\mathrm{Mb}$}

In order to insight understand the structural organization of the striped snake-head $\mathrm{Mb}$ and its structural-functional relationship, three-dimensional structure of the fish Mbs was constructed by using SWISS-MODEL, a homology modeling server, combined with Deep view program ${ }^{47}$. The ribbon structure of striped snake-head fish $\mathrm{Mb}$, as shown in Fig. 17 (a), indicates the characteristic of teleost $\mathrm{Mb}$ which the absent D-helix and the present of the random coil loop instead. While that of mammalian Mb contains D-helix (Fig. 17 (b)). This structural change of the D-helix may be a major contributing factor to the oxygen dissociation kinetics differences observed between teleost and mammalian $\mathrm{Mb}^{11,48}$.

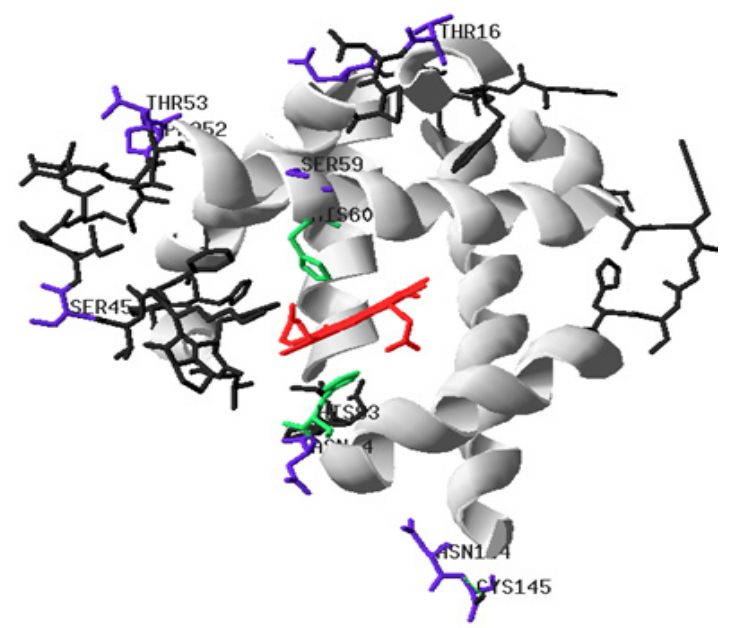

Fig. 19: The 0.91 Ă resolution ribbon structure showing amino acid residues which different from the conserved region of other fish $\mathrm{Mb}$ 
The $0.91 \AA$ resolution three-dimensional structures of the striped snake-head fish Mb which showed amino acid residues not in helices is shown in Fig. 18. This fish Mb maintains the characteristic tertiary globin fold found in other vertebrate Mbs along with the conserved architecture and environment of active site found in other species ${ }^{49}$, but difference in some residues which both forming in helical structure and not in helical one.

Typically, teleost Mbs have sets of two groups sharing a set of the conserved residues, particularly involved in oxygen-binding pocket and the interactions with the heme group. Also, the striped snake-head fish $\mathrm{Mb}$ contains these conserved residues at proximal histidine (His60) and distal histidine (His93) but difference in the amino acids located closed to them. Moreover, in some conserved area among the close evolution fish $\mathrm{Mb}$, the amino acid residues of $\mathrm{Mb}$ in the striped snakehead fish differ from those of Mbs. Fig. 19 shows three dimensional structure of the striped snakehead fish $\mathrm{Mb}$ which showed both different amino acid residues in the conserved area and amino acid residues not in helices.

The amino acid residues in the fish $\mathrm{Mb}$ sequence which differ from the conserved area of other fish Mb are Thr16, Ser45, Pro52, Thr53, Ser59, Asn94, Met107, Glu109, Asn144 and Cys145. Most of the residues have hydroxyl group in the molecule

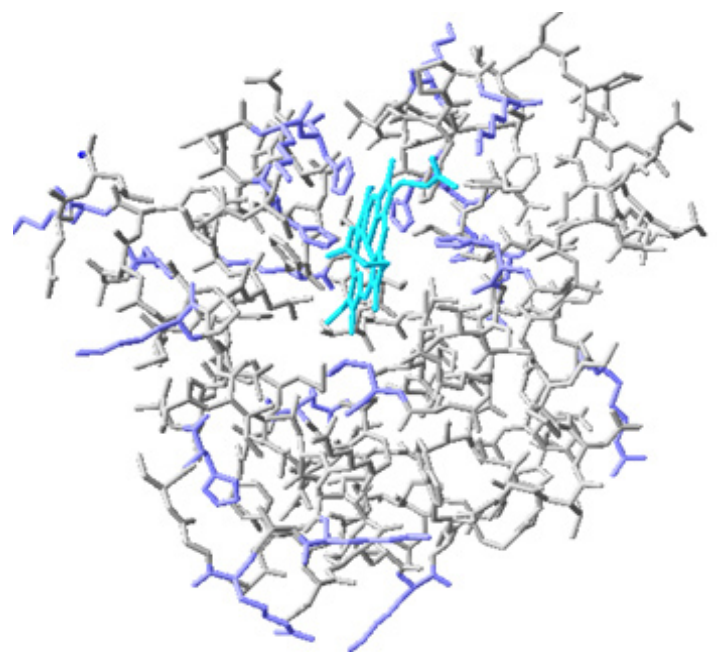

Fig. 20: The $0.91 \AA$ resolution Mb structure showing entire amino acid residues. Blue residues represent the hydrophilic amino acids but the amino acid residues at the same position in the conserved region of other fishes are non-polar residues ${ }^{50}$. The hydrophilic and hydrophobic residues in $\mathrm{Mb}$ structure of the striped snake-head fish are shown in Fig. 20. The modeling structure confirms that the outside of the Mb compact structure contains many hydrophilic residues which can form $\mathrm{H}$-bonding to other which help stabilize the structure of the fish $\mathrm{Mb}$. Therefore, the striped snake-head fish Mb may have a high stability. These suggestions may support the living habitat as either higher tolerance to hypoxia condition or high temperature water of the striped snake-head fish than other fishes.

Moreover, the distance between the distal $\mathrm{His}$, the proximal $\mathrm{His}$ and $\mathrm{Fe}$ atom in the heme pocket was investigated by using 3D molecule viewer exists in Vector NTI program. The distances between distal His-Fe atom and between proximal His -Fe atom are found to be $4.36 \AA$ and $5.61 \AA$, respectively (Fig. 21).

By comparison with some mammalian Mbs and other fish Mbs, the distance between distal $\mathrm{His}$ and $\mathrm{Fe}$ atom in the heme pocket of the striped snake-head fish $\mathrm{Mb}$ is shorter than that of sperm whale $\mathrm{Mb}$ and yellowfin tuna Mb (Table 4). Because the distal His has known to help stabilize the binding of $\mathrm{O}_{2}$ in $\mathrm{Mb}$ molecule, therefore the $\mathrm{Mb}$ structure of the striped snake-head Mb might serve strong binding of $\mathrm{O}_{2}$ molecule resulting in the tolerance in low $\mathrm{O}_{2}$ conditions of the fish. According to the distance between proximal His-Fe atom, the striped snake-head fish $\mathrm{Mb}$ gave shorter distance than yellowfin tuna $\mathrm{Mb}$ but longer distance than sperm whale $\mathrm{Mb}$. The result indicates that the fish $\mathrm{Mb}$ is easily unfolded compared to the mammalian $\mathrm{Mb}^{51}$.

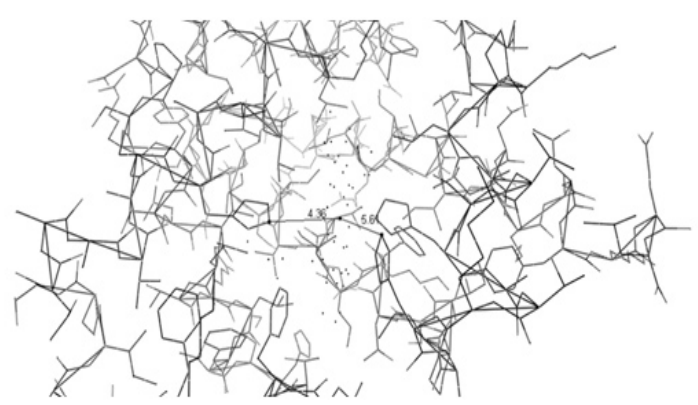

Fig. 21: The $0.91 \AA$ resolution Mb structure showing the distance between distal His $-\mathrm{Fe}$ atom and between proximal His -Fe atom 
Because the proximal His binds directly the Fe atom in the heme group with covalent bonding, the longer distance between these groups means the weaker interactions resulted less stability of the Mb structure. However, by comparing with that of yellowfin tuna, this fish Mb would exhibit higher stability.

\section{CONCLUSION}

The isolation and sequence analysis of cloned cDNA for Mb from striped snake-head fish revealed two lengths of nucleotide sequences different in $3^{\prime}$ untranslated regions ( $\mathrm{Mbl}$ and $\mathrm{Mbll}$ genes), probably the results of gene duplication. In accordance to amino acid coding region, both genes encoded protein with 145 amino acid residues which were different in two amino acid residues at position 114 and 117. The results may indicate that Mbs are expressed to be $\mathrm{Mb}$ isoforms. The deduced amino acid sequences of the fish Mbs were very close to those of various fish species. Comparing with some freshwater fish Mbs, these amino acid sequences are identical to goldfish, common carp and zebra fish. Moreover, they are slightly two residues shorter than other fish Mbs which had closely amino acid sequences. There are amino acid differences among the fish Mbs and other Mbs that occur in the highly conserved regions in fish species. Interestingly, the evolution of this fish $\mathrm{Mb}$ reveals that this novel $\mathrm{Mb}$ was very close to the active behavior of Atlantic blue marlin, yellowfin tuna and chub mackerel which have very high content of $\mathrm{Mb}$, but was not close to other freshwater fish. These evolution data corresponded to the highly active behavior of striped snake-head fish. This result may demonstrate that the facilitating of $\mathrm{O}_{2}$ diffusion may functional in the same manner as that of those sea fishes. Three-dimensional structure of the fish $\mathrm{Mb}$ reveals many hydrophilic residues located at the outside of molecule which can form $\mathrm{H}$-bond to other and thus held stabilizing the fish Mb structure. Furthermore, the distance between Fe atom and distal histidine at position 60 which is known for $\mathrm{O}_{2}$ binding stability of $\mathrm{Mb}$ is 4.36 $\AA$. This distance in the fish $\mathrm{Mb}$ is shorter than that of both sperm whale $\mathrm{Mb}$ and yellowfin tuna $\mathrm{Mb}$. This is possible that the fish Mb might be served in strong binding of $\mathrm{O}_{2}$.

\section{ACKNOWLEDGEMENTS}

The research funding supported by Center of Excellence for Innovation in Chemistry (PERCH$\mathrm{CIC})$, Commission on Higher Education, Ministry of Education, and Ratchamangakala University of Technology Isan, Khon Kaen, Thailand was gratefully acknowledged.

\section{REFERENCES}

1. Boonyaratparin, M.; Mccoy, E.W.; Chittapalapong, T. Food and agricultural organization of the United Nations. Project reports, Thailand. 1985.

2. Brown, W.D.; Martinez, M.; Johnstone, M.; Olcoyy, H.S. J. Biol. Chem. 1962,237, 8184.

3. Jones, N.B.; Wang, C.C.; Dwulet, E.F.; Lehman, D.L.; Meuth, L.J.; Bogardt, A.R.; Gurd, R.N.F. Biochim. Biophys. Acta-Protein structure 1979, 577, 454-463.

4. Kooyman, G.L.; Ponganis. P.J. Annu. Rev. Physiol. 1998, 60, 19-32.

5. Maeda, N.; Fitch, W.M. J. Biol. Chem. 1982, 257, 2806-2815.

6. Peter, W.M.; Michael, J.B.; Michael, E.V.; Robert, E.C. Comp. Biochem. Physiol. B2004, 137(3), 341-350.
7. Birnbaum, G.I.; Evans, S.V.; Przybylska, M.; Rose, D.R. Acta. Cryst. 1994, D50, 283289.

8. Chaijan, M.; Benjakul, S.; Visessanguan, W.; Faustman, C. Food. Chem. 2007, 100, 156164.

9. Steers, Jr. E.; Davis, Jr. R.H. Comp. Biochemi. Physiol B 1979, 62(4), 393-402.

10. Tsubamoto, Y.; Matsuoka, A.; Yusa, K.; Shimaka, K. Eur. J. Biochem. 1990, 193, 5559.

11. Kendrew, J.C.; Dickerson, R.E.; Strandberg, B.E.; Hart, R.G.; Davies, D.R.; Phillips, D.C.; Shore, V.C. Nature 1960, 185, 422-427.

12. Phillips, S.E.V.; Schoenborn, B.P. Nature 1981, 292, 81-82.

13. Marcinek, D.J.; Bonaventura, J.; Wittenberg, J.B.; Block, B.A. Am. J. Physiol. Reg. Integr. 
Comp. Physiol. 2001, 280, 1123-1133.

14. Wittenberg, B.A.; Wittenberg, J.B. J. Biol. Chem. 1975, 250, 9038-9043.

15. Wittenberg J. B.; Wittenberg, B. A. Annu. Rev. Biochem. 1981, 51, 857-878.

16. Edmunson, A. B. Nature 1965, 205, 883887.

17. Oord Van den, A.H.A.; Wesdorp, J.J.; Van dem, A.F.; Verheij, J.A. Euro. J. Biochem. 1969, 10, 140-145.

18. Awad, E.S.; Kotite, L. Biochem. J. 1966, 98, 909-914.

19. Maeda, N.; Fitch, W.M. J. Biol. Chem. 1981, 256, 4293-4300.

20. Dosi, R.; Maro, D.A.; Chambery, A.; Colonna, G.; Costantini, S.; Geraci, G.; Parente, A. Comp. Biochem. Physio. Part B 2006, 145, 230-238.

21. Chow, C-J.; Wu, J-C.; Lee, P.-F.; Ochiai, Y. Comp. Biochem. Physiol. B 2009, 154, 274281.

22. Ochiai, Y.; Watanabe, Y.; Ozawa, H.; Ikegami. S.; Uchida. N.; Watanabe, S. Biosci. Biotechnol. Biochem. 2010, 74, 1673-1679.

23. Ochiai, Y. WASET 2011, 74, 731-735.

24. Gidding, G.G. Crit. Rev. Food Sci. Techno. 1973, 35, 117-140.

25. Livingston, D.J.; Brown, W.D. Food Technol. 1981, 35(5), 244-252.

26. Postnikova, G.B.; Tselikova, S.V.; Kolaeva, S.G.; Solomonov, N.G. Comp. Biochem. Physiol. B 1999, 124(1), 35-37.

27. Roesner, A.; Mitz, S.A.; Hankeln, T.; Burmester, T. FEBS. J. 2008, 275, 3633-3643.

28. Chow, C.J. J. Agric. Food. Chem. 1991, 39, 22-26.

29. Ueki, N.; Ochiai, Y. Fish. Sci. 2004, 70, 875884.

30. Stewart, J.M.; Blakely, J.A.; Karpowicz, P.A.; Kalanxhi, E.; Thatcher, B.J.; Martin, B.M. Comp. Biochem. Physiol. B 2004, 137, 401412.

31. Fosmire, G.J.; Brown, W.D. Comp. Biochem. Physiol. 1976, 55B: 293-299.

32. Ueki, N.; Chaujen, C.; Ochiai, Y. J. Agric. Food. Chem. 2005, 53, 4968-4975.

33. Chen, L.C.; Lin, S.B.; Chen, H.H. Fish. Sci. 2004, 70, 293-298.

34. Dewilde, S.; Winnepennincks, B.; Arndt,
M.H.L.; Nascimento, D.G.; Santoro, M.M.; Miller, A.N.; Kerlavage, R.A.; Geoghagen, N.; Marck, E.V.; Liu, L.X.; Weber, R.E.; Moens, L. J. Biol. Chem. 1998, 273, 13583-13592.

35. Delmotte, N.; Mayr, B.; Leinenbach, R. K.; Kohbacher, O.; Klein, C.; Huber, C. J. Proteome Res. 2006, 414-421.

36. Schreiter, E.R.; Rodr Guez, M.M.; Weichsel, A.; Montfort. W.R.; Bonaventura, J. J. Biol. Chem. 2007, 282, 19773-19780.

37. Cossins, A.R.; Williams, D.R.; Foulkes, N.S.; Berenbrink, M.; Kipar, A. J. Exp. Biol. 2009, 212, 627-638.

38. Helbo, S.; Dewilde, S.; Williams, D.R.; Berghmans, H.; Berenbrink, M.; Cossins, A.R.; Fago, A. Am. J. Physiol. Reg. Integr. Comp. Physiol. 2012, 302, 693-701.

39. Ohno, S. Evolution by Gene Duplication. Springer Verlag, Berlin, 1970.

40. Wu, J.T.; Pleper, R.K.; Wu, L.H.; Peters, J.L. Adv. Clin. Chem. 1989, 35(55), 778-782.

41. Tachida, H.; Kuboyama, T. The Genetics Society of America 1998, 149, 2147-2158.

42. Chotichayapong, C.; Wiengsamut, K.; Chanthai, S.; Sattayasai, N.; Tamiya, T.; Kanzawa, N.; Tsuchiya, T. Fish Physiol. Biochem. 2012, 38(5): 1533-1543.

43. Shiraki, K.; Kudou, M.; Fujiwara, S.; Imanakab, T.; Takagi, M. J. Biochem. 2002, 132, 591595.

44. Hamoir, G.; Konosu ,S. Biochem. J. 1965, 96, 85-96.

45. Gibb, A.C.; Dickson, K.A. Integr. Comp. Biol. 2002, 42, 199-207.

46. Dickson, K.A.; Donley, J.M.; Sepulveda, C.; Bhoopat, L. J. Exp. Biol. 2002, 205, 969980.

47. Arnold, K.; Bordoli, L.; Kopp, J.; Schwede, T. Bioinformatics 2006, 22,195-201.

48. Madden, P.W.; Babcock, M.J.; Vayda, M.E.; Cashon, R.E. Comp. Biochem. Physiol. B 2004, 137, 341-350.

49. Philips, S.E. J. Mol. Biol. 1989, 142, 531554.

50. Macgregor, R.B.; Weber, G. Nature 1986, 319(6048), 70-73.

51. Chanthai, S.; Ogawa, M.; Tamiya, T.; Tsuchiya, T. Fish. Sci. 1996, 62, 927-932. 